Virginia Commonwealth University VCU Scholars Compass

2004

\title{
Equivalence Study of a Dental Anatomy Computer-Assisted Learning Program
}

Russell E. Bogacki

Virginia Commonwealth University

Al M. Best

Virginia Commonwealth University, albest@vcu.edu

Louis M.Abbey

Virginia Commonwealth University

Follow this and additional works at: http://scholarscompass.vcu.edu/peri_pubs

Part of the Periodontics and Periodontology Commons

Reprinted by permission of Journal of Dental Education, Volume 68, 8 (August 2004). Copyright 2004 by the American Dental Education Association.

\section{Downloaded from}

http://scholarscompass.vcu.edu/peri_pubs/9

This Article is brought to you for free and open access by the Dept. of Periodontics at VCU Scholars Compass. It has been accepted for inclusion in Periodontics Publications by an authorized administrator of VCU Scholars Compass. For more information, please contact libcompass@vcu.edu. 


\title{
Equivalence Study of a Dental Anatomy Computer-Assisted Learning Program
}

\author{
Russell E. Bogacki, D.D.S., M.S.; Al Best, Ph.D.; Louis M. Abbey, D.M.D., M.S.
}

Abstract: Tooth Morphology is a computer-assisted learning program designed to teach the anatomy of the adult dentition. The purpose of this study was to test whether Tooth Morphology could teach dental anatomy to first-year dental students as well as the traditional lecture. A randomized controlled trial was performed with forty-five first-year dental students. The students were randomly assigned to either the Tooth Morphology group $(\mathrm{n}=23)$, which used the computer-assisted learning program and did not attend lecture, or the lecture group $(\mathrm{n}=22)$, which attended the traditional lecture and did not use Tooth Morphology. The Tooth Morphology group had a final exam average of 90.0 (standard deviation=5.2), and the lecture group had a final exam average of $90.9(\mathrm{sd}=5.3)$. Analysis showed that the two groups' scores were statistically equivalent $(\mathrm{p}<0.05)$, with a priori equivalence bounds around the difference between the groups set at $+/-5$ points. It was concluded that Tooth Morphology taught the anatomy of the adult dentition as well as traditional lecture, as measured by exams. Based on the results of this study and student feedback, Tooth Morphology, in combination with interactive class meetings, has replaced the traditional dental anatomy lectures.

Dr. Bogacki is Assistant Professor, Department of General Practice, School of Dentistry; Dr. Best is Associate Professor, Department of Biostatistics, School of Medicine; and Dr. Abbey is Professor, Department of Oral Pathology, School of Dentistry - all at Virginia Commonwealth University. Direct correspondence and requests for reprints to Dr. Russell E. Bogacki, 520 North 12 ${ }^{\text {th }}$ Street, P.O. Box 980566, Richmond, VA 23298-0566; 804-828-2977 phone; 804-828-3159 fax; rbogacki@vcu.edu.

The Instructional Development Center of Virginia Commonwealth University provided support for supplies for this project.

Key words: dental education, randomized controlled trial, computer-assisted instruction, morphology

Submitted for publication 2/5/03; accepted 6/6/04

$\mathrm{D}$ ental anatomy at Virginia Commonwealth University (VCU) has been taught in the past using traditional lectures, with the faculty showing slides and describing the anatomical features of each tooth. The traditional lecture was acceptable, but there were problems that sometimes resulted in frustration for both students and faculty. Student evaluations reflected boredom. Each anatomical feature was reviewed in detail, and since the goal was for the student to memorize the anatomy of each tooth, very little creative thought was required. In addition, some students found the traditional lecture approach cumbersome because it failed to address all styles of learning, there was little interaction, and the lecture time was inconvenient. These are the characteristics of a course begging for fresh air and creative thinking. Some students thrive in an environment of memorization and facts, while others prefer more interaction and independence from the rigor of the classroom. The traditional way of teaching dental anatomy has little appeal to the latter group, yet this course is a foundation of dentistry. This article describes an attempt to offer students an alternative way to learn dental anatomy at VCU School of Dentistry.
Dental students are at least chronologically adults. Adults prefer to learn in an environment that is self-paced, interactive, full of robust feedback, and has as independent a schedule as possible. ${ }^{1,2}$ These preferences present both a challenge and an opportunity to improve the way dental anatomy is taught to adult dental students. Computer-assisted learning (CAL) has shown promise by introducing interactivity and independence into learning experiences. Enhancing learning with computer technologies began in the mid- to late $1960 \mathrm{~s} .{ }^{3,4}$ The literature tracing the historical development of CAL from that time to the present is extensive. A detailed review of the literature is beyond the scope of this article, but basically, the progress has been one of increasing and accelerated use of technology in all levels of education. Several studies have reviewed the broad spectrum of literature in this area. ${ }^{5,6} \mathrm{~A}$ recent article by Rosenberg et al. ${ }^{7}$ has reviewed a large portion of the CAL literature with a particular emphasis on dental education. Those authors, limiting their series to twenty-seven randomized controlled trials, recommended CAL be used as an adjunct to conventional teaching or as a means of self-instruction. Students responded positively to CAL and seemed motivated to learn. "Value-added" advantages to CAL included 
anytime/anywhere access, self-directed learning and review, and the programs were judged to be at least as effective as other methods of learning.

At VCU, a CAL course called Tooth Morphology was developed to teach dental anatomy. Tooth Morphology was envisioned to have several characteristics common to CAL:

- self-paced, independent, anytime/anywhere format;

- maximum interactivity;

- intuitive, easy-to-use interface;

- high-quality graphics;

- 3-dimensional effects; and

- testing and feedback.

Tooth Morphology uses text, photographic images, illustrations, and lectures to teach the morphology of the adult dentition. These features appeal to most learning styles. The program includes an introductory section containing six units on the adult dentition: the permanent dentition, tooth numbering, functional divisions, tooth names, tooth structure, and tooth views. There is also an individual section for each tooth consisting of six views: facial, lingual, mesial, distal, incisal, and internal. Dental terminology and self-assessment tests are integrated into the course, and an aural pronunciation guide is provided.

After thoroughly studying Tooth Morphology, the student is expected to be able to:

- name and identify all the teeth in the adult dentition;

- identify teeth using the Universal Notation System;

- locate teeth in the dental arch;

- identify major morphologic features of each tooth in the adult dentition; and

- use dental terminology related to dental anatomy.

Tooth Morphology consists of a single CD that functions on both PC and Apple computers. This allows students to use Tooth Morphology wherever they have access to an updated computer.

The study presented in this article tested the hypothesis that Tooth Morphology teaches dental anatomy as well as traditional lecture (equivalence). Equivalence trials are appropriate when comparing a new product to an established product, or when the new product has similar properties, but may have other advantages such as safety, cost, or ease of use. ${ }^{8}$ In this study, the established product is the traditional dental anatomy lecture and the new product is Tooth Morphology.

\section{Methods}

This study was a randomized controlled trial of forty-six first-year dental students enrolled for a six-week course in dental anatomy. Volunteers were recruited during the month before the course started by announcements sent by email, posted in their lecture hall, and by study information sessions. Informed volunteers, who consented to participate in the study, were randomly assigned into either the lecture group or the Tooth Morphology group using simple randomization. Simple randomization was achieved by using a computer to randomly assign subjects into either group. The Tooth Morphology group could not attend lecture, but had the Tooth Morphology CD and access to all other course material. The lecture group attended lecture just as they would have if they did not volunteer for the study, but did not have the Tooth Morphology CD. Students in the lecture group were asked not to use or view the Tooth Morphology CD during the study period. Both groups attended preexam review sessions, took the same exams at the same time in the same classroom, and had access to the dental anatomy course website. Since equivalence trials are sensitive to biases and require rigorous methods, this randomized controlled trial design, with simple randomization, was considered the best design. Students who did not volunteer for the study took the traditional lecture course and were not included in the equivalence analysis because they did not go through the randomization process.

Equivalence studies require the setting of equivalence bounds before the study starts. These bounds represent a reasonable range within which the average scores of the study groups are considered equal. The equivalence bounds were set at five points on a 100-point scale. The equivalence test is based on the 95 percent confidence interval around the difference between the two groups, which had to be within $+/-5$ points for the two groups to be equivalent. ${ }^{9}$ The two null hypotheses were: Ho: $\mathrm{D}<\mathrm{L}$ and $\mathrm{D}>\mathrm{U}$ and the alternative hypothesis was: $\mathrm{Ha}: \mathrm{L}<\mathrm{D}$ $<\mathrm{U}$, where $\mathrm{L}=$ lower bound, $\mathrm{D}=$ difference, and $\mathrm{U}$ $=$ upper bound. If the 95 percent confidence interval around the difference was between -5 and +5 , then the null hypotheses would be rejected, and the alternative hypothesis would be accepted indicating statistically significant equivalence. 


\section{Results}

A total of forty-six students volunteered for the study out of a class of eighty-three. One student left the school soon after volunteering. Of the remaining students, twenty-three were randomized into the Tooth Morphology group, and twenty-two into the lecture group. A description of the groups is detailed in Table 1. Chi-square analyses, with appropriate grouping, showed no statistically significant differences between the groups in the areas of gender, race, computer experience, or dental anatomy background. There was no statistically significant difference in age between the two groups as determined by a ttest. To summarize, simple randomization produced relatively balanced groups.

Table 2 displays the summary statistics for each study group and the students in the class who were not randomized to either study group. A t-test showed no statistically significant difference between the study participants and the rest of the class that did not participate in the study. The observed difference between the two study groups for the final average grade was 0.9 with a 95 percent confidence interval of -2.26 to +4.05 . In order to be equivalent, the 95 percent $\mathrm{CI}$ on the difference must be between -5 and +5 . Therefore, the null hypotheses were rejected, and the two study groups are statistically equivalent $(\mathrm{p}<0.05)$.

\section{Discussion}

Many previous studies on CAL used a superiority study design to compare CAL programs to traditional teaching techniques, but failed to achieve statistically significant findings because study groups usually had similar scores or outcomes. They sought to test whether or not CAL was better than traditional teaching techniques, which is difficult to prove and usually unnecessary. Some of these previous studies would then conclude, or imply, that the study groups were the same because a statistically significant difference was not found. This was flawed statistical thinking. Lack of a difference does not mean that the groups are the same; it means that there was not enough evidence to show that the groups were different enough to reject the null hypothesis of no difference. ${ }^{10}$ More evidence was needed to show a statistically significant difference, and this meant a larger sample size, which was often impossible. This study addressed this problem by testing for equivalence instead of superiority. Our goal was to test whether or not Tooth Morphology was as good as traditional lecture.

The equivalence study design solves the abovementioned problem, but there are difficulties with this approach. Equivalence studies can be biased to show equivalence. The selection of equivalence bounds can bias the results. If equivalence bounds are too wide, then the study groups can be shown to be statistically equivalent because the 95 percent confidence interval around the difference between the groups would always be within the bounds no matter what the size of the difference. Therefore, equivalence bounds must be set at logical, accept-

Table 1. Description of the study groups

\begin{tabular}{lcc} 
& \multicolumn{2}{c}{ Group } \\
\cline { 2 - 3 } Descriptor & $\begin{array}{c}\text { Tooth } \\
\text { Morphology }\end{array}$ & $\begin{array}{c}\text { Traditional } \\
\text { Lecture }\end{array}$ \\
\hline $\mathrm{n} \quad \begin{array}{c}20 \text { of } 23 \\
\text { responded }\end{array}$ & $\begin{array}{c}11 \text { of } 22 \\
\text { responded }\end{array}$ \\
\% Female & $39 \%$ & $23 \%$ \\
$\%$ Non-White* & $39 \%$ & $23 \%$ \\
Average Age* & 26 & 27 \\
Computer Experience* & & \\
$\quad$ No Previous Experience & 0 & 0 \\
$\quad$ Familiar & 9 & 5 \\
$\quad$ Very Familiar & 7 & 6 \\
$\quad$ Expert & 4 & 0 \\
Previous Dental Anatomy Training* & & \\
$\quad$ No Previous Training & 14 & 7 \\
$\quad$ Some Familiarity & 4 & 4 \\
$\quad$ Undergraduate Course & 2 & 0 \\
Expert & 0 & 0
\end{tabular}

*These data come from a post-study survey.

Table 2. Exam scores for each group: average and standard deviation

\begin{tabular}{lccc} 
& \multicolumn{3}{c}{ Group } \\
\cline { 2 - 4 } & $\begin{array}{c}\text { Tooth } \\
\text { Morphology } \\
(\mathrm{n}=23)\end{array}$ & $\begin{array}{c}\text { Traditional } \\
\text { Lecture } \\
(\mathrm{n}=22)\end{array}$ & $\begin{array}{c}\text { Rest of } \\
\text { Class } \\
(\mathrm{n}=37)\end{array}$ \\
\hline Exam 1 & $89.6(7.9)$ & $90.5(7.2)$ & $89.3(9.7)$ \\
Exam 2 & $91.0(6.0)$ & $92.7(5.9)$ & $89.7(9.0)$ \\
Exam 3 & $89.5(7.1)$ & $89.5(8.3)$ & $91.8(6.7)$ \\
Final Average & $90.0(5.2)$ & $90.9(5.3)$ & $90.3(6.9)$
\end{tabular}


able, points with the goal of avoiding this bias. Sample size can also bias the results. As the sample size increases, the 95 percent confidence interval around the difference between the study groups will decrease in size. If there is an unlimited supply of study subjects, then again almost any two groups can be found to be statistically equivalent. These two problems were avoided in this study because it had acceptable equivalence bounds set before the study started and an appropriate sample size. In fact, the sample size was smaller than hoped for based on a sample size analysis that took place before recruitment efforts started.

Crossover of the Tooth Morphology CD from the Tooth Morphology group to students in the traditional lecture group was a potential problem, but was reduced as much as possible by asking the students to avoid sharing the $\mathrm{CD}$ at the start of this study and by reminding them not to share throughout the study period.

The results suggest that the students who used Tooth Morphology did just as well as the students who attended lecture. This does not imply that Tooth Morphology can now replace dental anatomy faculty or that students only have to use Tooth Morphology to learn dental anatomy. It does mean, however, that faculty can now spend more time interacting with students and providing robust feedback on each student's learning experience as needed. Faculty must be available to help students through periods of misunderstanding, point out subtle details that might be missed, and tie in clinical relevance to the subject. For example, faculty can help students see the importance of preserving transverse and oblique ridges and maintaining contact points in their restorative treatment, keeping furcations in mind when they perform periodontal treatment, and understanding the relationship between root form and occlusion. The implications are exciting for a subject that is difficult to make exciting in the traditional lecture format.

The results also suggest that CAL may be used to teach other subjects similar to dental anatomy in their unchanging nature. Subjects that might be adapted are gross anatomy, basic pathology, histology, biochemistry, and genetics. The traditional lecture can be replaced with interactive class meetings, which will improve the efficiency of the faculty and open the opportunity to introduce clinical relevance. These meetings can be beneficial for students who need help, whereas students who quickly learn the material can devote more time to subjects they find to be more difficult, which opens the possibility of more self-directed learning. These meetings also afford the faculty an opportunity to provide feedback to students as the course progresses.

Many students provided comments about their experiences with Tooth Morphology in their course evaluations. All were positive, but some provided additional feedback that will help with the implementation of CAL. Many appreciated the flexibility provided to them by being in the Tooth Morphology group because they could learn the material when it was convenient for them. One student mentioned that he learns better later in the day and that the lectures would not have been as helpful to him as the CD. Another student mentioned the issue of self-discipline with regard to studying, which is a struggle for this individual. Traditional lectures force students to be exposed to the subject matter on a regular basis. With the CD, this student did not study on a regular basis and had to cram for exams. The problem of discipline can be addressed, and has been in this course, by having students take frequent online quizzes, which will motivate them to keep up with the material and prepare adequately for exams.

\section{Conclusion}

This study showed that Tooth Morphology is statistically equivalent to the traditional dental anatomy lecture in its ability to teach dental anatomy, as measured by exams. Many of the proposed advantages of CAL are now being realized at VCU. Tooth Morphology, in combination with interactive class meetings, has replaced the traditional dental anatomy lectures. The advantages of this approach include greater student-faculty interaction, greater student control over pace, more time for faculty to help struggling students and introduce clinical relevance, less time maintaining course materials, and less expense. It is hoped that CAL programs will be developed for other subjects following the model set by Tooth Morphology.

\section{Acknowledgments}

The authors would like to thank Dr. Linda Baughan for developing Tooth Morphology. She worked with a team of programming, instructional design, and artistic support experts at VCU's Instructional Development Center. 


\section{REFERENCES}

1. Newble DI, Entwistle NJ. Learning styles and approaches: implications for medical education. Med Educ 1986;20:162-75.

2. Wlodkowski RJ. Enhancing adult motivation to learn. San Francisco: Jossey-Bass, 1999.

3. Atkinson R. Computerized instruction and the learning process. Am Psychol 1968;23:225-39.

4. Suppes P, Morningstar M. Computer-assisted instruction. Science 1968;166:343-50.

5. Looking at technology in context: a framework for understanding technology and education research. In: Berliner DC, Calfee RC, eds. The handbook of educational psychology. New York: Macmillan, 1996:807-40.
6. Dede C, ed. Introduction. In: Yearbook: learning with technology. Alexandria, VA: Association for Supervision and Curriculum Development, 1998.

7. Rosenberg H, Grad HA, Matear DW. The effectiveness of computer-aided, self-instructional programs in dental education: a systematic review of the literature. J Dent Educ 2003;67:524-32.

8. Gunsolley JC, Elswick RK, Davenport JM. Equivalence and superiority testing in regeneration clinical trials. J Periodontol 1998;69:521-7.

9. International Conference on Harmonisation: tripartite guideline. Statistical Principles for Clinical Trials 1998; 14-6.

10. Altman DG, Bland JM. Absence of evidence is not evidence of absence. BMJ 1995;311:485. 